\title{
The Populus holobiont: dissecting the effects of plant niches and genotype on the microbiome
}

\author{
M. A. Cregger ${ }^{1 \dagger}$, A. M. Veach ${ }^{1 \dagger}$, Z. K. Yang ${ }^{1}$, M. J. Crouch $^{1,4}$, R. Vilgalys ${ }^{2}$, G. A. Tuskan ${ }^{1}$ and C. W. Schadt ${ }^{1,3^{*}}$
}

\begin{abstract}
Background: Microorganisms serve important functions within numerous eukaryotic host organisms. An understanding of the variation in the plant niche-level microbiome, from rhizosphere soils to plant canopies, is imperative to gain a better understanding of how both the structural and functional processes of microbiomes impact the health of the overall plant holobiome. Using Populus trees as a model ecosystem, we characterized the archaeal/bacterial and fungal microbiome across 30 different tissue-level niches within replicated Populus deltoides and hybrid Populus trichocarpa $\times$ deltoides individuals using 165 and ITS2 rRNA gene analyses.

Results: Our analyses indicate that archaeal/bacterial and fungal microbiomes varied primarily across broader plant habitat classes (leaves, stems, roots, soils) regardless of plant genotype, except for fungal communities within leaf niches, which were greatly impacted by the host genotype. Differences between tree genotypes are evident in the elevated presence of two potential fungal pathogens, Marssonina brunnea and Septoria sp., on hybrid P. trichocarpa $\times$ deltoides trees which may in turn be contributing to divergence in overall microbiome composition. Archaeal/bacterial diversity increased from leaves, to stem, to root, and to soil habitats, whereas fungal diversity was the greatest in stems and soils.

Conclusions: This study provides a holistic understanding of microbiome structure within a bioenergy relevant plant host, one of the most complete niche-level analyses of any plant. As such, it constitutes a detailed atlas or map for further hypothesis testing on the significance of individual microbial taxa within specific niches and habitats of Populus and a baseline for comparisons to other plant species.
\end{abstract}

Keywords: Populus deltoides, Populus trichocarpa $\times$ deltoides hybrid, 165 rRNA, ITS2, Fungal pathogen

\section{Background}

Microorganisms are ubiquitous across all environments, yet we are just beginning to understand the role they play within ecosystems and in association with host organisms. Individual plant-associated microorganisms are known to aid in key functions across the entire plant, e.g., water and nutrient acquisition [1], stress response [2], suppression of pathogens [3], and reducing herbivory directly and through priming of host plant defenses [4]. As a result, the collective holobiomes or phytobiomes of plants are gaining increased

\footnotetext{
* Correspondence: schadtcw@ornl.gov

${ }^{\dagger}$ Equal contributors

'Biosciences Division, Oak Ridge National Laboratory, 1 Bethel Valley Rd, Oak Ridge, TN 37831, USA

${ }^{3}$ Microbiology Department, University of Tennessee, M409 Walters Life

Sciences, Knoxville, TN 37996, USA

Full list of author information is available at the end of the article
}

attention [5, 6]. Although advances are being made in understanding microbiome composition within individual host habitats [7-13], little work has been conducted to holistically understand the variation in microbiome composition across the numerous potential microbial niches represented by multiple plant organ and tissue types [5].

Populus has become the model woody perennial organism for researchers interested in testing mechanistic hypotheses related to plant-microbe interactions. Populus is amenable to experimentation because of its fast growth rates and the ability to be propagated vegetatively. Populus has its full genome sequenced [14, 15]; therefore, the interaction between host genomic information and microbial associations is readily discernible. Further, understanding these interactions may be particularly important socioeconomically as poplar trees currently are cultivated 
for pulp and paper production [16, 17] and have potential as a cellulose-derived biofuel feedstock [14, 18-20].

Distinct microbiome composition of the Populus rhizosphere and root endosphere across environmental gradients [21, 22] and between Populus genotypes or species [23] has been demonstrated. Microbial community isolates from Populus have also been shown to enhance the health, growth, and development of their plant hosts [24-26]. Differentiation between root endosphere and rhizosphere microbial communities is likely due to selection of unique microbial consortia with the ability to penetrate and survive the host environment [21], although the strength of selection may differ between microbial groups. However, the degree of microbiome specificity across all plant-associated niches (i.e., soil to canopy) has not been effectively tested within Populus genotypes or between genotypes.

There are known pathogenic organisms that differentially attack Populus species and genotypes (e.g., P. trichocarpa $\times$ deltoides), and pathogen population abundance has been shown to vary among Populus species [27] and across genotypes within species [28]. Fungal pathogen abundance in Populus leaves has also been shown to be correlated with the co-occurrence of alternate fungal endophyte species that likely act as antagonists and competitors for both space and host resources [28, 29]. Understanding the basis of multi-pathogen resistance and the degree of pathogen interactions with the overall phytobiome may aid in the success of effectively growing Populus for pulp fiber and biofuel feedstock operations and understanding Populus contributions to ecosystem services.

Using Populus as a model system, this study seeks to understand how the collective communities of archaea/ bacteria and fungi, or the microbiome, varied across habitats within a tree host from soil to tree canopy and between individual Populus deltoides and Populus trichocarpa $\times$ deltoides hybrids (ramets) under identical environmental conditions. We characterized microbial communities across 30 different plant-associated niches covering an extensive number of the aboveground and belowground tissue-level microbial habitats, as well as both shallow and deeper soil habitats (Additional file 1: Table S1), using amplicon 16S and ITS2 rRNA genetargeted Illumina MiSeq sequencing. We hypothesized that due to differing microbial inoculum sources (i.e., air-leaf/stem interface vs. the root-soil interface) and environmental filtering mechanisms (e.g., tissue chemistry or exudates in roots [30]), microbiome niche-level composition for archaea/bacteria and fungi would vary across the landscape represented by the ecosystem of whole trees. Further, due to differences in susceptibility of different Populus species to fungal pathogen infection, we hypothesized that microbial communities would differ between Populus deltoides and the Populus trichocarpa $\times$ deltoides hybrid.

\section{Methods}

\section{Study location and sampling methods}

Trees used in this study were harvested from an experimental cultivar trial in Blount County Tennessee at a site managed by the University of Tennessee Institute of Agriculture (UTIA)-East Tennessee Research and Education Center (ETREC) located at $35^{\circ} 50^{\prime} 39^{\prime \prime} \mathrm{N} / 83^{\circ} 57^{\prime} 36^{\prime \prime} \mathrm{W}$. Soils in the area of harvest were verified to be Inceptisols of the Emory Series with transitions from A horizon silt loams to $B$ horizon silt clay loams taking place at approximately $25 \mathrm{~cm}$. Five matched replicates of clonal individuals of $P$. deltoides and five $P$. trichocarpa $\times$ deltoides hybrid (10 trees total) were selected on the border of adjacent experimental blocks. Trees were harvested on August 14-15, 2014, nearing the end of their third season of growth. Each tree was felled using a chainsaw onto a plastic tarp. The stump, roots, and surrounding soil (approximately $100-\mathrm{cm}$ diameter, $75-\mathrm{cm}$ depth) were removed by a hydraulic tree spade and placed onto a separate tarp for dissection and processing. Thirty different plant-associated habitat types were defined and processed as outlined below across the 10 trees $(N=300$; Additional file 1: Table S1 and Figure S1). Sample processing took place in both the field and laboratory. Field processed samples (e.g., soils, leaf swabs) were transported on blue ice and frozen at $-80{ }^{\circ} \mathrm{C}$ on the same day. Laboratory processed samples were stored in a $4{ }^{\circ} \mathrm{C}$ cold room until processing was completed as below.

\section{Host niche definitions and sample preparation}

Root samples were extracted from shallow $(0-30 \mathrm{~cm})$ and deep $(30-75 \mathrm{~cm})$ depths of each tree's root ball and stored at $4{ }^{\circ} \mathrm{C}$ until processed (within 4 days). Bulk soil was sampled from the same depth interval from the edge of the excavation hole, placed on ice and frozen at $-80{ }^{\circ} \mathrm{C}$ in the laboratory the same day until DNA was extracted. In the laboratory, shallow and deep roots were washed three times with $200 \mathrm{~mL}$ of $0.1 \%$ sterile Tween 20 and then separated by diameter classes into fine $(<2 \mathrm{~mm})$ and coarse ( 5-20 mm-termed secondary throughout the remainder of the text) roots. Soil attached to shallow and deep roots (referred to as shallow and deep rhizosphere habitats in the remainder of the text) was pelleted by centrifugation in 50-ml tubes and then frozen at $-80{ }^{\circ} \mathrm{C}$ until DNA was extracted. These root classes were then surfacesterilized as described previously [21, 22]. Structural roots $(>5 \mathrm{~cm})$ from the two depths were also collected and processed identically to stem samples (described below). All root endosphere samples were verified as surfacesterile by streaking subsampled material across an R2A agar plate and incubating overnight at room temperature to check for the appearance of colonies. Samples with colonies present had this sterilization procedure repeated. 
Given our root sterilization procedure used sodium hypochlorite which has been shown to remove $~ 98 \%$ of microbes on the exterior of roots [31], we were unable to characterize the rhizoplane-associated microbial community.

Three stem sections from each annual growth increment, as identified by successive terminal bud scars, were collected and separated in the field, transported on ice, and then stored in a cold room at $4{ }^{\circ} \mathrm{C}$ until processed (within 10 days). In the laboratory, each stem and structural root section sample was wiped down with sterile $0.1 \%$ Tween 20 solution. Samples from each growth year $(1,2$, and 3$)$ were then dissected into three habitat categories: outer stem layer (i.e., bark, cambium, and phloem tissue), living developing xylem, and mature xylem tissue and preserved at $-80^{\circ} \mathrm{C}$ until DNA extraction.

Leaf samples were collected from terminal (developing leaves, LPI 2-4) and sub-terminal (mature leaves, LPI $7-$ 10) along multiple branches. The top surfaces (developing and mature upper phyllosphere) and bottom surfaces (developing and mature lower phyllosphere) of each leaf sample were then separately swabbed in the field with wooden applicators moistened with sterile $0.1 \%$ Tween 20 , and swabs frozen at $-80{ }^{\circ} \mathrm{C}$ upon arrival to the laboratory, while leaves were stored at $4{ }^{\circ} \mathrm{C}$ until processing (within 6 days). Leaf and petioles were then separated and washed (developing whole leaf wash and mature whole leaf wash) and surface-sterilized (developing and mature leaf endosphere, developing and mature petiole endosphere) as described above for roots (Additional file 1: Table S1) and frozen at $-80{ }^{\circ} \mathrm{C}$ until DNA extraction. Due to storage time differences (i.e., frozen the day of sampling versus stored at $4{ }^{\circ} \mathrm{C}$ for several days prior to dissection or processing), we compared mean differences between significantly different leaf habitat comparisons (e.g., developing whole leaf phyllosphere [DWL, leaf phyllosphere washes up to 6-days storage] versus upper phyllosphere developing [UPD, leaf swabs frozen at day 0]) for alpha diversity ANOVAs and beta diversity (NMDS scores) ANOVAs. Leaf habitats differed, and had similar mean differences, between those that were sampled in the same timeframe and those sampled at different timeframes (e.g., bacterial diversity DWL vs UPD and DWL vs LEM mean difference $=0.23, p=0.02$ ). Therefore, storage time differences likely did not significantly alter our results.

\section{DNA extractions and Illumina MiSeq sequencing}

All plant tissues (i.e., roots, stems, and leaves) were cut into fine pieces $(<5 \mathrm{~mm})$ prior to DNA extraction. Rhizosphere samples, whole-leaf washes, and upper and lower phyllosphere samples were centrifuged at 10,000 rcf for $10 \mathrm{~min}$, and the supernatant was removed. These samples and bulk soil samples had $250 \mathrm{mg}$ of material extracted using the MoBio PowerSoil DNA Isolation Kit (MoBio Laboratories, Inc., Carlsbad, CA, USA). All other tissue types had $50 \mathrm{mg}$ of tissue per extraction and were bead-beaten for $3 \mathrm{~min}$ in frozen (liquid nitrogen) blocks using one 5-mm steal bead per extraction (Qiagen, Venlo, the Netherlands). Following these steps, pulverized tissue was extracted using the MoBio PowerPlant Pro DNA Isolation Kit (MoBio Laboratories, Inc., Carlsbad, CA, USA). Stem tissue samples had two replicate extractions per sample to achieve sufficient DNA yields. All extractions were quantified on a NanoDrop 1000 spectrophotometer (NanoDrop Products, Wilmington, DE, USA). Aboveground tissues (i.e., leaves and stems) were also purified and concentrated using Zymo DNA Clean and Concentrator-5 Kit (Zymo Research Corporation, Irvine, CA, USA) and quantified again prior to PCRs.

We used a two-step PCR approach to barcode tag templates with frameshifting nucleotide primers [32] with the following modifications. Forward and reverse primer mixtures were modified to maximize phylogenetic coverage of archaea, bacteria, and fungi (Additional file 1: Table S2), thus allowing full and simultaneous assessment of bacteria, fungi, and archaea due to the increased coverage of our primer sets. Primers for tagging bacterial amplicons were a mixture of 9 forward and 6 reverse 515F and 806R primers for the 16S rRNA V4 gene region at equal concentrations $(0.5 \mu \mathrm{M}$; Additional file 1: Table S2). Primers for tagging fungal ITS2 rRNA region included a mixture of 11 forward and 7 reverse primers at equal concentration $(0.5 \mu \mathrm{M}$; Additional file 1: Table S2). To inhibit plant material amplification, we added a mixture of peptide nucleotide acid (PNA) blockers oligos (PNA Bio Inc., Thousand Oaks, CA, USA) targeted at plant mitochondrial and chloroplast $16 \mathrm{~S}$ rRNA genes and plant 5.8S nuclear rRNA gene upstream of ITS2 region primers in fungal PCRs (see Lundberg et al. [32]; Additional file 1: Table S2 and Figure S2). The mitochondrial PNA of Lundberg et al. [32] was adjusted for a 1 bp mismatch in Populus, whereas the nuclear 5.8S PNA was custom-designed for this study. Thermal cycler conditions for the primary PCRs for soils were 5 cycles of $95{ }^{\circ} \mathrm{C}$ for $1 \mathrm{~min}, 50{ }^{\circ} \mathrm{C}$ for $2 \mathrm{~min}$, and $72{ }^{\circ} \mathrm{C}$ for $1 \mathrm{~min}$. Primary PCR conditions for plant tissues were 5 cycles of $95^{\circ} \mathrm{C}$ for $1 \mathrm{~min}, 78{ }^{\circ} \mathrm{C}$ for $5 \mathrm{~s}, 50{ }^{\circ} \mathrm{C}$ for $2 \mathrm{~min}$, and $72{ }^{\circ} \mathrm{C}$ for $1 \mathrm{~min}$. Primary PCR products were cleaned with $17 \mu \mathrm{L}$ of Agencourt AMPure beads and eluted in $21 \mu \mathrm{L}$ of nuclease-free water. Secondary PCRs had purified DNA tagged with barcoded reverse primers and forward primers (Additional file 1: Table S2) in the $50 \mu \mathrm{L}$ reaction, except with $20 \mu \mathrm{L}$ of purified DNA from primary PCRs. Thermal cycler conditions for secondary soil PCRs consisted of denaturation at $95{ }^{\circ} \mathrm{C}$ for $45 \mathrm{~s}$ followed by 32 cycles of $95{ }^{\circ} \mathrm{C}$ for $15 \mathrm{~s}$, annealing at $60{ }^{\circ} \mathrm{C}$ for $30 \mathrm{~s}, 72{ }^{\circ} \mathrm{C}$ for $30 \mathrm{~s}$, and final extension at $72{ }^{\circ} \mathrm{C}$ for $30 \mathrm{~s}$. Secondary PCRs for plant tissue consisted of denaturation at $95{ }^{\circ} \mathrm{C}$ for $45 \mathrm{~s}$, followed by 32 cycles of $95{ }^{\circ} \mathrm{C}$ for $15 \mathrm{~s}, 78{ }^{\circ} \mathrm{C}$ for $5 \mathrm{~s}$, with remaining cycle parameters the same as with soil secondary PCRs. 
After PCRs, experimental units were pooled based on agarose gel band intensity and purified with Agencourt AMPure XP beads (beads to DNA, 0.7 to 1 ratio; Beckman Coulter Inc., Pasadena, CA, USA). Illumina MiSeq sequencing was carried out using a $9 \mathrm{pM}$ amplicon concentration including a 15\% PhiX spike with 500 (v. 2; $2 \times 250$ ) cycles.

\section{Illumina MiSeq sequence processing}

Paired-end sequences (.fastq) were joined and demultiplexed using QIIME default settings except a Phred quality threshold of Q20 [33]. Forward and reverse primers were then removed using the cutadapt program [34]. For ITS2 sequences, reads were truncated to $200 \mathrm{bp}$ and any sequences less than $200 \mathrm{bp}$ were filtered. Both $16 \mathrm{~S}$ and ITS2 sequences were quality-filtered (fastq_maxee $=0.5$ ), derepelicated, and had singletons removed in USEARCH [35]. Operational taxonomic units (OTUs) were then clustered at $97 \%$ similarity after chimeras were removed in USEARCH [35]. Lastly, using QIIME [33], OTUs were classified using BLAST with the Greengenes (V13.8) and UNITE reference databases (V7.1; [36] for archaeal/bacterial and fungal communities, respectively). Contaminant sequences that were unclassified at domain (bacteria/archaea) or kingdom (fungi), mitochondria, chloroplasts, plant, and protista, were filtered. Complete datasets across habitat comparisons were rarefied at 1000 sequences for bacteria and 2000 for fungi to minimize sample loss (see rarefaction curves-Additional file 1: Figures S3-S4). The final full community dataset had 7458 OTUs and 269,000 sequences for bacteria and 9277 OTUs and 546,000 sequences for fungi. After the full dataset was analyzed, leaf, stem, root, and soil compartments were separated to examine differences within these compartments and each rarefied separately to maximize sequence number and minimize sample loss. Leaf, stem, and root samples were rarefied at 500 sequences for bacteria and 1000 sequences for fungi. Soil samples were rarefied at 35,000 for bacteria and 5000 sequences for fungi. OTU diversity was calculated in QIIME as the complement of Simpson's Diversity $\left(1-D=1-\Sigma p_{\mathrm{i}}^{2}\right)$ with $p_{\mathrm{i}}$ representing the frequency of each OTU within a sample.

\section{Statistical analysis}

We determined if the relative abundance of dominant fungal pathogens differed across leaf tissue habitats and genotypes (OTUs identified as Mycosphaerella/Septoria sp. and Marssonina brunnea), and whether dominant $(\geq 0.1 \%)$ archaeal/bacterial and fungal phyla differed across broad habitat categories (i.e., leaf, stem, root, and soil), and between genotypes using two-way ANOVA models. We also used two-way ANOVAs to test if both archaeal/bacterial and fungal OTU diversity differed across habitats and between genotypes. Microbial diversity data was arc-sine transformed prior to ANOVAs. Since some phyla's relative abundance was skewed, we used $\log _{10}$-transformed data to meet assumptions of normality prior to statistical analysis. Since multiple tests were run, each type 1 error rate for each ANOVA model was FDR-corrected for multiple comparisons. ANOVA models were performed in $R$ (aov function, R Project for Statistical Computing, Vienna, Austria).

Microbial community composition was assessed by computing Bray-Curtis dissimilarity matrices and then visualized using non-metric dimensional scaling (NMDS) ordinations to visualize compositional differences. To test whether habitat, genotype, or their interaction had a significant effect on community composition, a permutational multivariate ANOVA (perMANOVA; [37]) with 10,000 permutations was calculated. NMDS and perMANOVA models were performed in Primer-E (Quest Research Limited, New Zealand). We also calculated perMANOVA pairwise comparisons within habitats and genotypes for leaf, stem, root, and soil communities separately for bacteria and fungi (pairwise.perm.manova in package RVAideMemoire; [38]). Lastly, we performed an indicator species analysis [39] using OTU abundance data to determine which OTUs occurred more frequently between habitats (i.e., leaf, stem, root, soil), genotype for all habitats (DD vs. TD), and genotype within a habitat (e.g., leaf DD vs. leaf TD) for bacterial and fungal communities (multipatt function in indicspecies package; [39]). After indicator OTUs were detected, an FDR correction was applied for post hoc multiple comparisons of statistical significance.

We used FUNGuild [40] to classify each OTU into an ecological guild to determine if fungal functional groups differed in relative abundance between genotypes within each broad habitat category (leaf, stem, root, soil). OTUs identified to a guild with a confidence ranking of "highly probable" or "probable" were retained in our analysis, whereas those with "possible" were considered unclassified. Furthermore, OTUs designated in more than one guild, with confidence, were placed in a "> 1 guild" category, but we do not report any results on this group of fungi. Undefined guilds, such as undefined pathogens, refer to pathogens not specific to fungi, plants, or animals, and undefined saprotrophs refer to saprotrophs not specific to wood, plant, or litter soil. A one-way ANOVA model was used to determine if dominant guilds within a habitat differed between plant genotypes. In this analysis, we included animal, plant, and undefined pathogens; soil, wood, and undefined saprotrophs; and fungal parasites, endophytes, arbuscular mycorrhizae, and ectomycorrhizae. Ericoid mycorrhizae were rarely detected in our dataset (i.e., present at low abundance within eight samples across all habitats); therefore, we did not include this guild in our analysis. 


\section{Results}

Microbial community composition shifts across habitat and tree genotype

Across the four broad habitats sampled (i.e., leaf, stem, root, soil), we found significant differences in both archaeal/bacterial $\left(R^{2}=0.30\right)$ and fungal $\left(R^{2}=0.24\right)$ community composition (Fig. 1, Table 1). A small amount of variation in community composition was also explained by genotype (bacterial $R^{2}=0.02$, fungal $R^{2}=0.03$ ) and the habitat $\times$ genotype interaction (bacterial $R^{2}=0.04$, fungal $R^{2}=0.08$, Table 1$)$. Archaeal/bacterial alpha diversity was greatest in soil habitats and lowest in leaf habitats (Fig. 2). Stem and root had similar bacterial alpha diversity estimates $(p=0.25)$. Fungal alpha diversity was greater in stems than in leaf or root habitats $(p \leq 0.01)$, whereas fungal alpha diversity was also greater in soils than roots (Tukey's HSD, $p=0.05$; Fig. 2). Archaeal/bacterial alpha diversity did not differ between Populus genotypes, but we found significant differences in alpha fungal diversity between Populus genotypes. Fungal diversity was greater in P. deltoides than in the hybrid (Fig. 2).

Within each broad habitat, the main effect of finer-scale habitat (within leaf, stem, roots, soils separately referred to as niche in remainder of text; Fig. 3) explained more variation than genotype or their interaction (Table 2), except for leaf fungal communities. Genotype explained more variation in leaf fungal community composition than niche $\left(R^{2}=0.21\right)$. Furthermore, across leaf, root, and soil communities, niche was more influential for archaeal/bacterial composition than fungal, whereas in stem communities, niche explained more variation in fungal communities compared to archaeal/bacterial communities (Table 2). The main effect of genotype generally explained similar amounts of variation for archaea/bacteria and fungi across specific niches, except for leaf communities (Table 2). Archaeal/bacterial diversity also differed among niches within each broad tissue/habitat type (e.g., whole-leaf washes had lower diversity than upper phyllosphere in developing tissues), but did not differ between genotypes within each niche across the broad tissue/habitat types (Additional file 1: Tables S5-S8). Fungal diversity differed between niches within broad habitat types, except roots. Further, niches within leaves, stems, and root communities differed in fungal diversity between genotype ( $p \leq 0.04$; Additional file 1: Tables S9-S11), where $P$. deltoides had greater fungal diversity, on average, compared to the hybrid (Fig. 2).

\section{Phylum level differences across habitat and tree genotype}

Twenty-one dominant ( $\geq 0.1 \%$ relative abundance) archaeal/bacterial phyla, and classes for Proteobacteria, were detected across this study (Additional file 1: Table S12). Twenty of these 21 dominant archaeal/bacterial phyla differed across broad habitats (i.e., leaves, stem, roots, and soil; $F_{3,267}=12.55, p \leq 0.01$, Fig. 3). Fusobacteria is the only dominant phyla that did not differ across these habitats (Additional file 1: Table S12). Crenarchaeota, Firmicutes, Nitrospirae, AD3, and WS3 had greater abundance in soils than in roots, stems, and leaves (Tukey's HSD: $p \leq 0.01$ ). The most common archaeal phyla identified, the Crenarchaeota, differed significantly across all tested habitats. The Crenarchaeota had $0.3 \%$ relative abundance in the leaves, $0.1 \%$ relative abundance in the stems, $0.2 \%$ abundance in the roots, and $3.0 \%$ relative abundance in the soil. Acidobacteria, Chloroflexi, Planctomycetes, Verrucomicrobia, and Deltaproteobacteria had the greatest abundance in soil versus other habitats, but also had greater abundance in roots than in stems and leaves (Tukey's HSD: $p \leq 0.01$ ). Gemmatimonadetes had the greatest abundance in soil, and root habitats had greater abundance compared to stem tissues (Tukey's HSD: $p \leq 0.01$ ). Bacteroidetes had the greatest

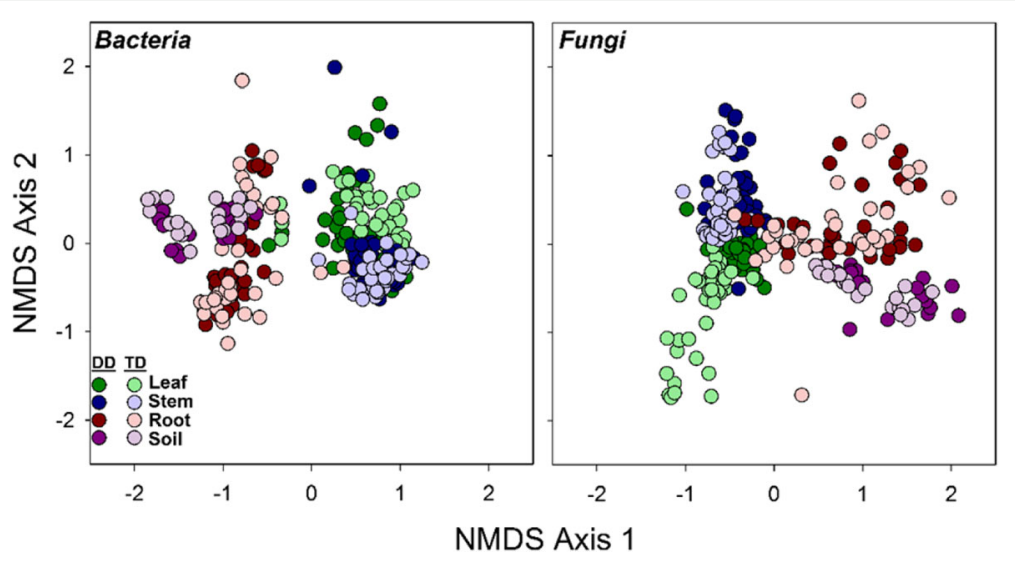

Fig. 1 NMDS ordinations of both archaeal/bacterial and fungal communities across the four broad habitat classifications (leaves, stems, roots, soil) and genotypes ( $P$. deltoides, $P$. trichocarpa $\times$ deltoides hybrid). Darker colors represent $P$. deltoides (DD) samples, whereas respective light colors represent hybrid samples (TD). Based on perMANOVA results, habitat was more influential for archaeal/bacterial and fungal community composition than genotype (Table 1) 
Table 1 Permutational multivariate ANOVA results with Bray-Curtis distance matrices implemented to partition sources of variation in this study (habitat, genotype, interaction between habitat and genotype $(\mathrm{H} \times \mathrm{G}))$ for both archaeal/bacterial and fungal communities. All samples were included therefore the main effect of habitat represents the broad categories of leaves, stems, roots, and soils. Statistical significance $(P($ perm $)$ ) computed based on sequential sums of squares from 9999 permutations

\begin{tabular}{lllllll}
\hline Community & Source of variation & SS & MS & $R^{2}$ & Pseudo- $F$ & P(perm) \\
\hline Bacteria & Habitat & 307,710 & 102,570 & 0.30 & 40.3 & 0.0001 \\
& Genotype & 18,469 & 18,469 & 0.02 & 7.3 & 0.0001 \\
& Interaction & 41,533 & 13,844 & 0.04 & 0.0001 \\
& Residuals & 663,810 & 2543.3 & 0.64 & & \\
Fungi & Total & $1,036,500$ & & 1 & 32.2 & 0.0001 \\
& Habitat & 246,890 & 82,295 & 0.24 & 0.3 & 0.0001 \\
& Genotype & 26,376 & 26,376 & 0.03 & 0.0001 \\
& Interaction & 79,953 & 26,651 & 0.08 & 0.65 & 10.4 \\
\hline
\end{tabular}

abundance in roots and stems compared to leaves and soil habitats, whereas TM7 had the greatest abundance in root habitats compared to all other habitats (Tukey's HSD: $p \leq 0.01)$. Actinobacteria and Armatimonadetes had greater abundance in soils, roots, and stems than in leaves, whereas TM6 had greater abundance in soils, roots, and leaves than in stem habitats (Tukey's HSD: $p \leq 0.01)$. Phylum FBP had greatest abundance in stem tissues (Tukey's HSD: $p \leq 0.01$ ). Alphaproteobacteria also had the greatest abundance in stem tissues. Leaves were enriched in Alphaproteobacteria compared to roots and soil and in root tissues compared to soil habitats (Tukey's HSD: $p \leq 0.03$; Additional file 1: Table S12). Betaproteobacteria were most abundant in soils and roots than in leaves or stems. Leaves were enriched in Betaproteobacteria compared to stems (Tukey's HSD: $p \leq 0.03)$. Gammaproteobacteria were most abundant in roots and leaves than in soils and stem habitats (Tukey's HSD: $\mathrm{p} \leq 0.01$ ). Actinobacteria were more abundant in $P$. deltoides-associated tissue/habitats, whereas TM7 were more abundant in the hybrid $(p \leq 0.03)$.

All six fungal phyla were found in this study (Fig. 4, Additional file 1: Table S12). Basidiomycota, Chytridiomycota, and Glomeromycota were most abundant in stem habitats (Tukey's HSD: $p \leq 0.01$ ). Ascomycota were most abundant in leaves and lowest in soils contrary to Rozellomycota and the former Zygomycota, which were most abundant in soils (Tukey's HSD: $p \leq 0.01$ ). No fungal phyla differed in abundance between tree genotypes.

\section{Functional fungal guild and OTU differences across tree genotype}

Several functional guilds' relative abundance differed between genotypes. Within soils, one functional guild differed between genotypes. Soil saprotrophs had greater relative abundance in the hybrid genotype compared to
P. deltoides $\left(F_{1,39}=4.45, p=0.04\right)$, but soil saprotrophs had, on average, low abundance $(0.08 \%)$. In roots, undefined pathogens were greater in the hybrid genotype $\left(F_{1,63}=5.96, p=0.02\right)$, but at very low abundance (undefined pathogens: $0 \%$ in $P$. deltoides, $0.03 \%$ in hybrids). In stems, low-abundance guilds, such as animal pathogens $\left(F_{1,85}=5.51, p=0.02\right)$ and fungal parasites $\left(F_{1,85}=16.66, p<0.001\right)$, were greater in hybrids compared to $P$. deltoides $(0.1 \%, 0.4$ vs. $0.03 \%$, $0.03 \%$, respectively), but abundant plant pathogens were approximately $2 \times$ greater in $P$. deltoides compared to the hybrid genotype $\left(F_{1,85}=16.20, p<0.001\right.$; $18.2 \%$ mean relative abundance in $P$. deltoides vs. $8.9 \%$ in $P$. trichocarpa $\times$ deltoides). Leaves had greater animal pathogens $\left(F_{1,81}=4.08, p=0.05\right)$, endophytes $\left(F_{1,81}=7.81, p=0.007\right)$, and undefined saprotrophs in $P$. deltoides tissue $(0.02 \%, 0.06 \%, 6.4 \%)$ compared to hybrid plants $(0.01 \%, 0.02 \%, 1.6 \%$, respectively). Interestingly, plant pathogen relative abundance did not differ between genotypes in leaf tissues $(9.2 \% \quad P$. deltoides, $8.7 \%$ hybrids; $p=0.810$ ).

Several OTUs were detected for both bacteria and fungi that significantly differed across habitats and between genotypes (Table 3). Across broad habitat categories, there were four OTUs that were indicative of leaf habitats, specifically Pseudomonas sp. and OTUs with highest taxonomic affinity to Ascomycota $(p \leq 0.01)$. BLASTn confirmed these classifications and identified the Ascomycota OTUs as Marssonina brunnea. One fungal indicator was found for stem habitats, classified in Chytridiomycota using UNITE, but classified as unicellular algae in BLASTn, so this OTU may potentially be a contaminant. Three indicator taxa existed for root tissues-Pseudomonas sp., Codineaopsis sp., and an uncultured ascomycete (Table 3). The same two fungal OTUs (OTU 2, 14988), which were indicators for leaf 


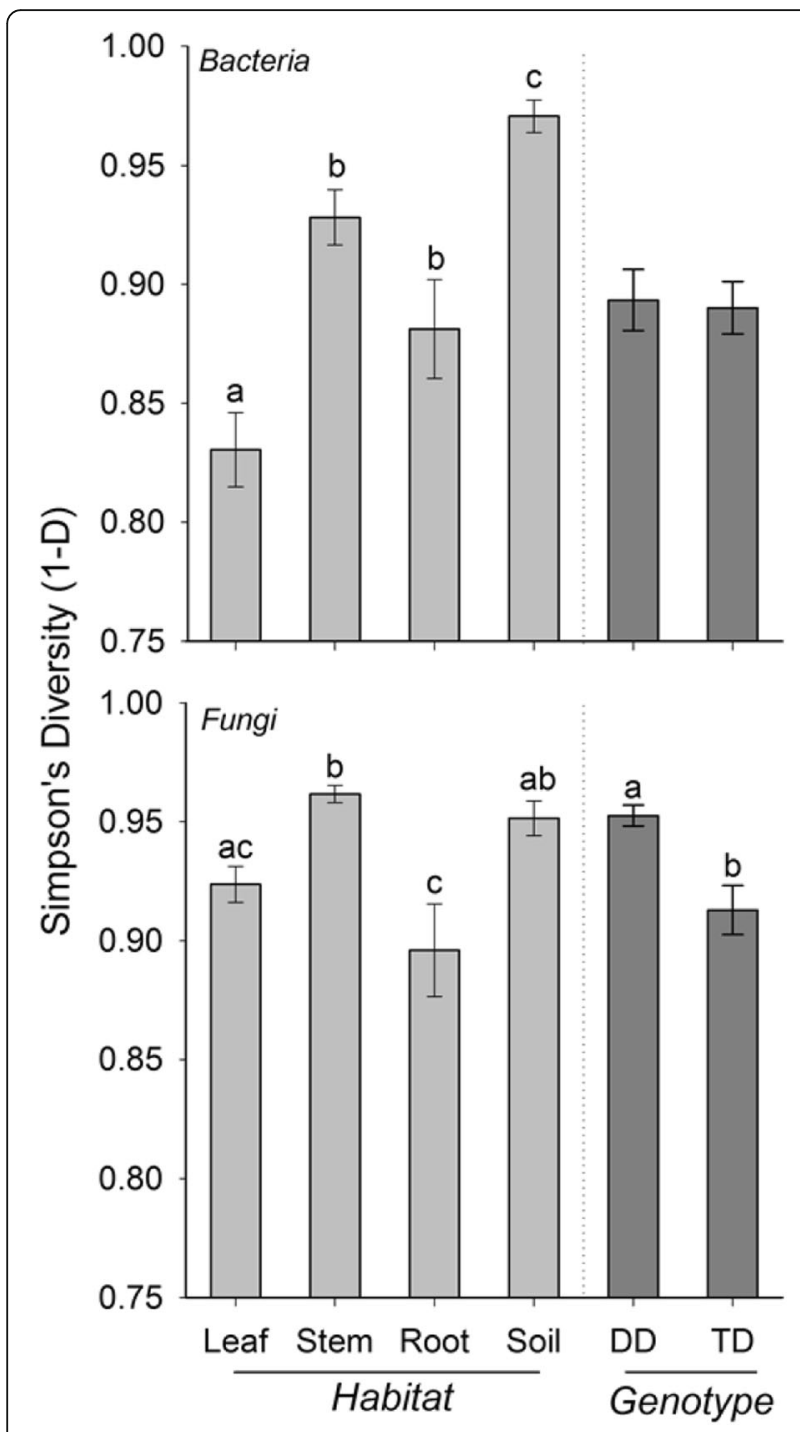

Fig. 2 Simpson's (1 -D) diversity across broad habitats (leaf, stem, root, and soil—denoted in light gray) and genotypes $(\mathrm{DD}=P$. deltoides, $\mathrm{TD}=$ P. trichocarpa $\times$ deltoides - denoted in dark gray) for both archaeal/ bacterial and fungal communities. For both archaea/bacteria and fungi, diversity differed across habitats $(p \leq 0.01)$. Fungal diversity differed between genotypes $(p \leq 0.01)$. Letters denote significant differences based on Tukey's HSD post hoc comparison tests. Diversity was arcsine square root transformed prior to analysis, but raw data average and standard errors per habitat and genotype are shown

tissue (Marssonina brunnea), were also indicators for the $P$. trichocarpa $\times$ deltoides hybrid across all broad habitat categories (relative abundance 7.1 and $13.4 \%$, respectively; Table 3). Within leaf communities, several fungal OTUs were indicators for hybrid genotype tissues and were classified as Marssonina brunnea via BLASTn. Further, one fungal OTU, Telletiopsis washingtonensis, was an indicator for $P$. deltoides leaf tissue. Lastly, within stem communities, two bacteria OTUs-Curtobacterium flaccumfaciens and Elsinoe banksiae-were indicators for hybrid stem tissue (Table 2). The relative abundance of both Septoria sp. and Marssonina brunnea, common Populus pathogens, differed across leaf niches and genotypes (Additional file 1: Tables S3-S4). Notably, both potential fungal pathogens were significantly greater in relative abundance in hybrid ramets (Fig. 5).

\section{Discussion}

This study demonstrates that the Populus microbiome significantly differs across the soil-root-stem-leaf landscape (Additional file 1: Table S12) and at a finer scale (within each of these niches; Fig. 3). Both archaeal/bacterial and fungal community composition shifted more so across habitats than between tree genotype when considering broad habitat classifications (i.e., soils, roots, stems, and leaves; Table 1) indicating environmental filtering (e.g., tissue specific filters) as a strong selective force for microbial communities across these environments. However, the fungal microbiome within leaf habitats varied more so between genotypes compared to habitat (Table 2), likely influenced by the dominance of two fungal pathogens, Marssonina brunnea and Septoria sp., within leaves (Fig. 5 and Table 3). These pathogens likely impacted turnover of microbial populations within the susceptible hybrid ramets. Bacterial diversity was greater in soils relative to roots, and aboveground habitats, but contrary to this, fungal diversity was similar between soils, stems, and leaves, whereas stem fungi had greater diversity compared to leaves and roots (Fig. 2). These results suggest not only that niche-based processes (i.e., habitat selection) largely drive both archaeal/bacterial and fungal community assembly across plant tissues, but also that specific mechanisms of assembly (e.g., niche partitioning, life history strategies) differ for archaea/bacteria and fungi across the Populus environment. However, due to amplification issues with specific tissues (i.e., rarefying at 500 sequences for bacterial communities), conclusions regarding microbial diversity may be limited in this particularly study and warrant further validation.

\section{Habitat selection effects}

Assembly of plant-associated microbial communities may be driven by niche-based processes, specifically plant genetic factors [41], acquisition via tissue-level selection, or stochasticity [42]. We observed significant differences in microbial diversity and community composition across broadly defined habitats (Figs. 1, 2, 3, and 4), and within these habitat categories (Additional file 1: Tables S5-S11). This agrees with our hypotheses that microbial communities would vary across the plant niches surveyed and is likely due to differences in regional species pools that colonize the various habitats (e.g., soil for roots, rainfall and aerial dispersal for leaves and stems) and niche partitioning as an outcome of microbial life history differences. 

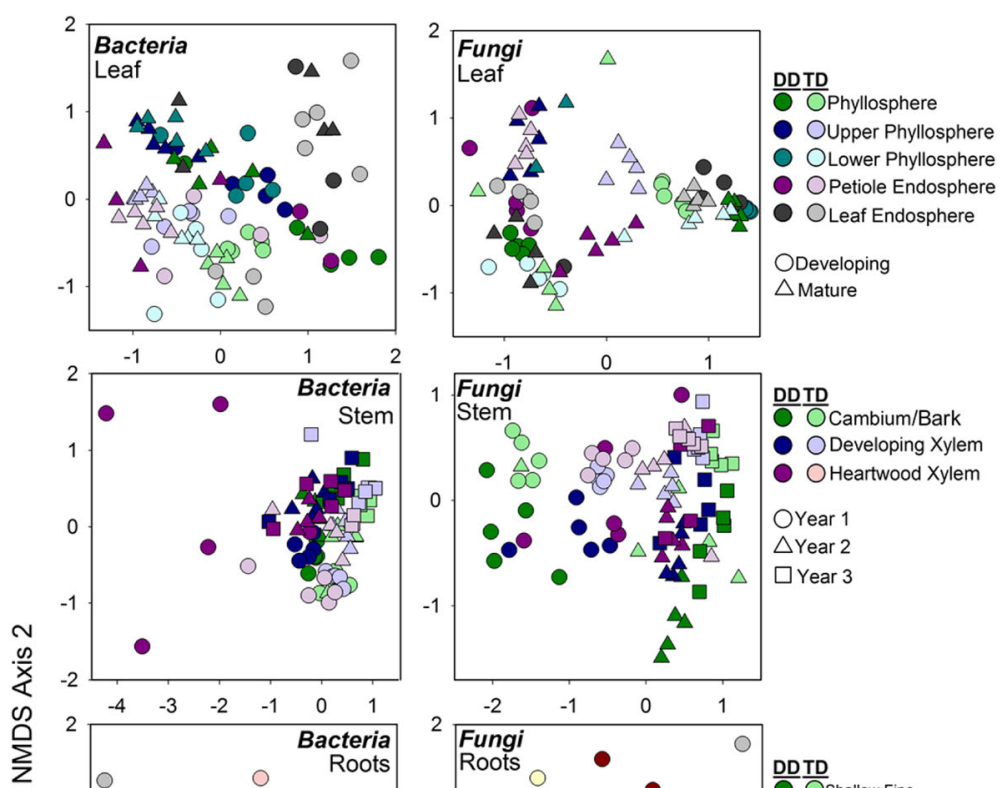

\section{DDTD}

OShallow Fine

Oshallow Second.
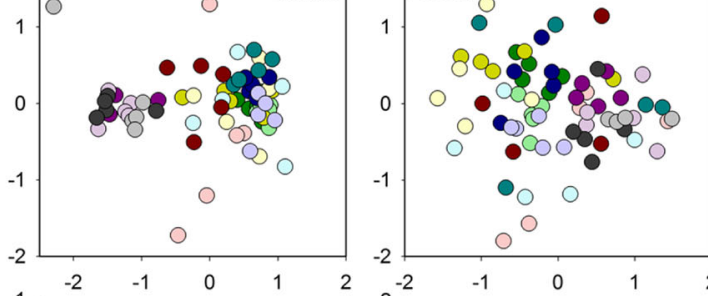

ODeep Fine

ODeep Second.

Ostruct. Cambium/Bark

- Ostruct. Dev. Xylem

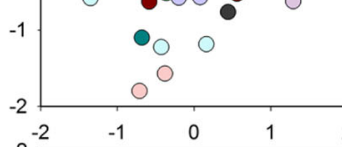

Ostruct. Heart. Xylem
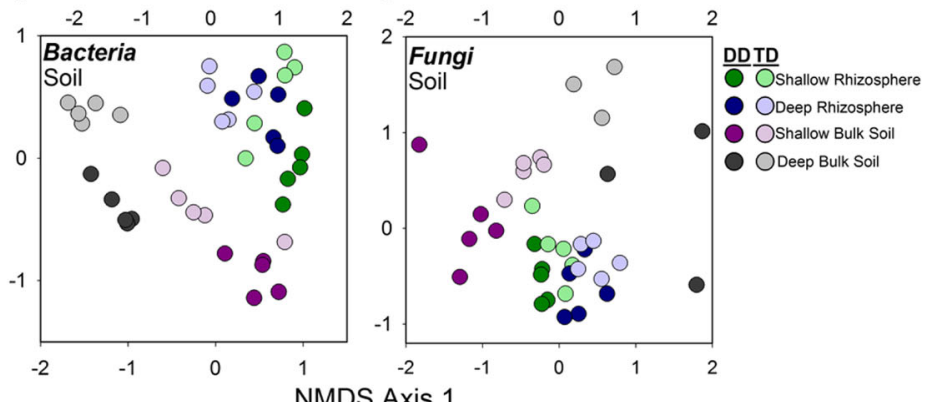

Fig. 3 NMDS ordination of both archaeal/bacterial and fungal communities across all 30 leaf, stem, root, and soil niches and Populus genotypes (P. deltoides, $P$. trichocarpa $\times$ deltoides hybrid). Darker colors represent $P$. deltoides (DD) samples whereas respective light colors represent hybrid samples (TD). For leaf communities: circles $=$ developing leaf samples and triangles = mature leaf samples. For stem communities: circles $=$ year 1 , triangles $=$ year 2 , and squares = year 3 samples. Niche was most influential for archaea//bacterial communities for leaves and stems, whereas genotype was most influential for fungal communities in leaves only. Niche was more influential for fungi in stems (Table 2). For roots and soils, in both archaeal/bacterial and fungal communities, niche was more influential than genotype (Additional file 1: Table S12)

The variation attributed to habitat, or plant tissue type, as a control on community composition indicates the strength of biotic (plant selection) or abiotic drivers of microbiome differentiation. Selection of microbial members across habitats are likely due to (1) interplay with Populus biochemical products [43], (2) mutualistic associations via plant growthpromoting microbes, or (3) large differences in abiotic factors such as nutrient availability and light exposure within aboveground tissues compared to belowground [6]. The latter may be especially relevant for the differences in archaeal/bacterial and fungal diversity across habitats. Fungal species, which are generally more tolerant to desiccation compared to bacteria, may proliferate under harsh environments (e.g., phyllospheres). Due to stress tolerance, or perhaps more overlap in fungal niche requirements, a greater degree of coexistence may exist for fungal communities within aboveground tissue [44].

Consistent with other studies, microbial diversity differed between plant-associated habitats, and common bacterial and fungal phyla were seen across each of the habitats that were broadly comparable to other plant hosts $[7,8,45]$. Leaves were primarily dominated by Alphaproteobacteria and Ascomycota, the latter in part likely due to the highly abundant Marssonina brunnea and Septoria musiva-like 
Table 2 Permutational multivariate ANOVA results with Bray-Curtis distance matrices implemented to partition sources of variation in this study (niche, genotype, interaction between niche and genotype $(\mathrm{N} \times \mathrm{G}))$ for both archaeal/bacterial and fungal communities. Leaves, stems, roots, and soil communities were analyzed separately; therefore, habitat effects refer to finer-scale niches within these respective broad habitat categories. Statistical significance (P(perm)) was computed based on sequential sums of squares from 9999 permutations

\begin{tabular}{|c|c|c|c|c|c|c|c|}
\hline Community & Habitat & Source of variation & SS & MS & $R^{2}$ & Pseudo- $F$ & $P($ perm) \\
\hline \multirow[t]{5}{*}{ Bacteria } & Leaves & Niche & 78,980 & 8775.6 & 0.29 & 5.0 & 0.0001 \\
\hline & & Genotype & 26,849 & 26,849 & 0.10 & 15.2 & 0.0001 \\
\hline & & $N \times G$ & 37,557 & 4173 & 0.14 & 2.4 & 0.0001 \\
\hline & & Residuals & 125,080 & 1761.7 & 0.46 & & \\
\hline & & Total & 272,940 & & 1.00 & & \\
\hline \multirow[t]{5}{*}{ Fungi } & Leaves & Niche & 48,697 & 6087.1 & 0.21 & 5.6 & 0.0001 \\
\hline & & Genotype & 72,650 & 72,650 & 0.32 & 66.9 & 0.0001 \\
\hline & & $N \times G$ & 29,836 & 3729.5 & 0.13 & 3.4 & 0.0001 \\
\hline & & Residuals & 73,840 & 1085.9 & 0.32 & & \\
\hline & & Total & 229,760 & & 1.00 & & \\
\hline \multirow[t]{5}{*}{ Bacteria } & Stem & Niche & 58,966 & 7370.8 & 0.31 & 5.4 & 0.0001 \\
\hline & & Genotype & 19,362 & 19,362 & 0.10 & 14.3 & 0.0001 \\
\hline & & $N \times G$ & 20,049 & 2506.2 & 0.10 & 1.8 & 0.0001 \\
\hline & & Residuals & 92,356 & 1358.2 & 0.48 & & \\
\hline & & Total & 191,000 & & 1.00 & & \\
\hline \multirow[t]{5}{*}{ Fungi } & Stem & Niche & 90,054 & 11,257 & 0.36 & 7.0 & 0.0001 \\
\hline & & Genotype & 22,613 & 22,613 & 0.09 & 14.0 & 0.0001 \\
\hline & & $N \times G$ & 21,776 & 2722 & 0.09 & 1.7 & 0.0001 \\
\hline & & Residuals & 114,460 & 1612.1 & 0.46 & & \\
\hline & & Total & 249,640 & & 1.00 & & \\
\hline \multirow[t]{5}{*}{ Bacteria } & Roots & Niche & 81,253 & 13,542 & 0.39 & 6.9 & 0.0001 \\
\hline & & Genotype & 6752.2 & 6752.2 & 0.03 & 3.4 & 0.0001 \\
\hline & & $N \times G$ & 13,966 & 2327.6 & 0.07 & 1.2 & 0.0213 \\
\hline & & Residuals & 106,410 & 1970.6 & 0.51 & & \\
\hline & & Total & 210,180 & & 1.00 & & \\
\hline \multirow[t]{5}{*}{ Fungi } & Roots & Niche & 53,637 & 8939.5 & 0.20 & 2.8 & 0.0001 \\
\hline & & Genotype & 9286 & 9286 & 0.04 & 2.9 & 0.0001 \\
\hline & & $N \times G$ & 23,063 & 3843.8 & 0.09 & 1.2 & 0.0183 \\
\hline & & Residuals & 177,350 & 3167 & 0.67 & & \\
\hline & & Total & 263,340 & & 1.00 & & \\
\hline \multirow[t]{5}{*}{ Bacteria } & Soil & Niche & 41,055 & 13,685 & 0.51 & 18.9 & 0.0001 \\
\hline & & Genotype & 8807.4 & 8807.4 & 0.11 & 12.2 & 0.0001 \\
\hline & & $N \times G$ & 7020.7 & 2340.2 & 0.09 & 3.2 & 0.0001 \\
\hline & & Residuals & 23,182 & 724.5 & 0.29 & & \\
\hline & & Total & 80,066 & & 1.00 & & \\
\hline \multirow[t]{5}{*}{ Fungi } & Soil & Niche & 28,882 & 9627.3 & 0.31 & 5.9 & 0.0001 \\
\hline & & Genotype & 8470.1 & 8470.1 & 0.09 & 5.2 & 0.0001 \\
\hline & & $N \times G$ & 8920.8 & 2973.6 & 0.10 & 1.8 & 0.0001 \\
\hline & & Residuals & 45,882 & 1638.6 & 0.50 & & \\
\hline & & Total & 92,296 & & 1.00 & & \\
\hline
\end{tabular}


Table 3 Indicator species analysis for bacterial and fungal OTUs across all samples (all samples community) and in leaf and stem communities. No indicator OTUs were detected for root or soil communities. Only dominant OTUs ( $\geq 1.0 \%$ relative abundance across samples) are given

\begin{tabular}{|c|c|c|c|c|c|c|}
\hline Community & Treatment & OTU no. & DB classification & BLASTn classification & Identity percentage/E-value & Relative abundance \\
\hline All samples & Leaf & 6 & Pseudomonas sp. & Pseudomonas sp. & $100 / 3 e-128$ & 2.2 \\
\hline All samples & Leaf & 14 & Pseudomonas sp. & Pseudomonas oryzihabitans strain* & $100 / 3 e-128$ & 1.9 \\
\hline All samples & Leaf & 2 & Ascomycota & Marssonina brunnea & 100/6e-99 & 4.3 \\
\hline All samples & Leaf & 14,988 & Ascomycota & Marssonina brunnea & $100 / 5 e-95$ & 2.2 \\
\hline All samples & Stem & 16 & Chytridiomycota & Trebouxia impressa & 100/6e-99 & 1.3 \\
\hline All samples & Root & 11,331 & Pseudomonas sp. & Pseudomonas sp. & $98 / 1 e-121$ & 1.3 \\
\hline All samples & Root & 10,451 & Codinaeopsis sp. & Codinaeopsis sp. ${ }^{* *}$ & 99/2e-94 & 1.6 \\
\hline All samples & Root & 42 & Ascomycota & Uncultured fungus & $98 / 3 e-72$ & 1.1 \\
\hline All samples & TD & 2 & Ascomycota & Marssonina brunnea & 100/6e-99 & 4.3 \\
\hline All samples & TD & 14,988 & Ascomycota & Marssonina brunnea & $100 / 5 e-95$ & 2.2 \\
\hline Leaf & DD & 66 & Exobasidiomycetes & Telletiopsis washingtonensis & 100/6e-99 & 1.1 \\
\hline Leaf & TD & 14,988 & Ascomycota & Marssonina brunnea & $100 / 5 e-95$ & 13.4 \\
\hline Leaf & TD & 2 & Ascomycota & Marssonina brunnea & 100/6e-99 & 7.1 \\
\hline Leaf & TD & 6721 & Ascomycota & Marssonina brunnea & $99 / 1 e-90$ & 1.7 \\
\hline Leaf & TD & 2744 & Ascomycota & Marssonina brunnea & 99/7e-89 & 1.1 \\
\hline Leaf & TD & 3701 & Ascomycota & Marssonina brunnea & $98 / 7 e-89$ & 1.0 \\
\hline Leaf & TD & 19,038 & Ascomycota & Marssonina brunnea & 100/8e-93 & 1.0 \\
\hline Stem & TD & 151 & Microbacteriaceae & Curtobacterium flaccumfaciens strain & $100 / 3 e-128$ & 1.6 \\
\hline Stem & TD & 14,143 & Sphaceloma protearum & Elsinoe banksiae & $96 / 7 e-84$ & 2.6 \\
\hline
\end{tabular}

*Representative sequence also had significant alignments with Pseudomonas psychrotolerans strains (identity percentage $=100 \%$, E-value $=3 \mathrm{e}-128$ ) ${ }^{*}$ Representative sequence also had significant alignments with Codinaea acacieae and Fusarium sp. However, all other high-quality hits were either with Codinaeopsis sp. or Chaetosphaeriales, the order Codinaeopsis belongs in (identity percentage $=99 \%$, E-value $=2 \mathrm{e}-94$ )

pathogens, both ascomycetes. Stem tissues were likewise dominated by these groups, but also were enriched in Actinobacteria and Basidiomycota, Chytridiomycota, and Glomeromycota (Additional file 1: Table S12). Gammaproteobacteria and Actinobacteria, as well as representatives of the former fungal Zygomycota, were most abundant in root tissues (Table 2). Many of these same taxa were reported in Populus trichocarpa roots as part of the Populus genome study [14]. Surprisingly, based on fungal guild designations, we found less than $2 \%$ of fungi classified as mycorrhizal (both arbuscular and ectomycorrhizae) across tree genotypes. This result is surprising as both AM and ECM fungi readily colonize poplar tree roots [46]. However, due to plant pathogens dominating plant tissues, albeit primarily stems and roots, their presence may have prevented significant recruitment of beneficial mycorrhizae. In addition, chemical cues, such as phenolic compound production, common in Populus, may trigger fungal pathogen growth at low concentrations $[47,48]$ and therefore cause significant species turnover in the microbiome.

Within some of the niches, there were indications that microbial function varied significantly across tissues and between tree genotype. For example, within Populus deltoides first-year heartwood xylem, there was a surprisingly large divergence from other similar stem niches (Fig. 3) that was driven by a large number of Firmicutes $(\sim 20 \%)$, of which $11 \%$ were from a single Lactobacillus classified OTU. Multiple studies have suggested that heartwood environments (especially wetwood characteristic of Populus trees) can turn anoxic and harbor organisms capable of fermentation, nitrogen fixation, and methanogenesis [49-52]. However, heartwood formation in these 3-year-old trees was likely incomplete as this event does not generally occur in Populus until years 3 to 5 depending on rate of growth $[53,54]$. Our results suggest we may be observing the beginnings of this change and its effects within this understudied microbial niche.

\section{Populus genotype effects}

Between $P$. deltoides and $P$. trichocarpa $\times$ deltoides genotypes, we observed significant differences in both fungal diversity and composition within the broad habitat categories that are likely driven by greater fungal pathogen abundances in the hybrid trees (Fig. 2, Fig. 5). While cursory examination of the site had revealed characteristic Septoria stem cankers on the trees prior to the study (C. Schadt, personal observation), the high pathogen load and 


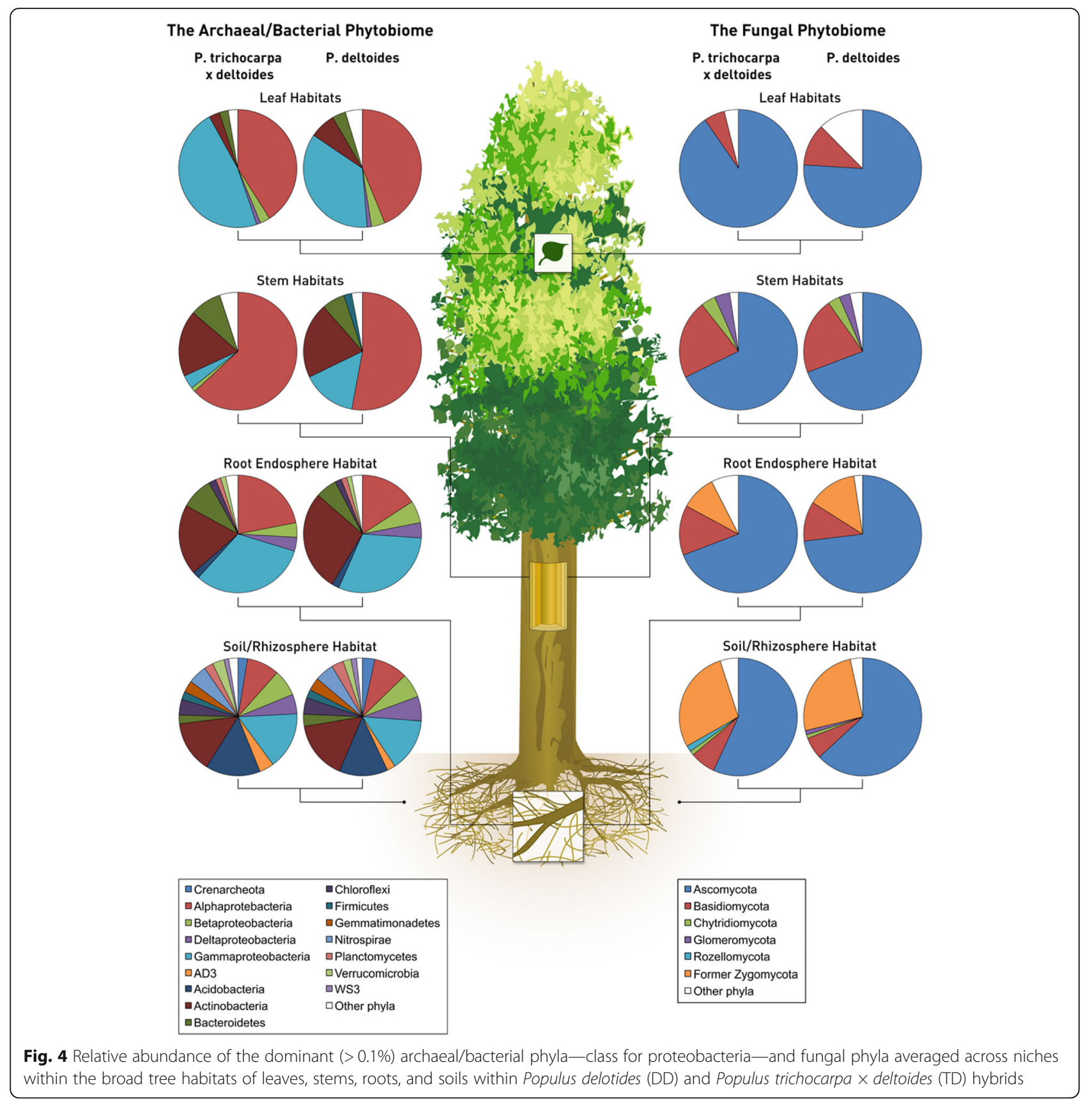

co-occurrence of both Septoria and Marssonina OTU within the hybrid trees was surprising and not recognized prior to the molecular analyses as we had assumed the leaf spots were also caused by Septoria. P. deltoides are resistant to certain sympatric fungal pathogens due to coevolution in the Eastern USA [55], whereas the hybrid trees are susceptible due to lack of co-occurring pathogens in the Western USA [27]. Indeed, the severity of loss from Septoria stem cankers and premature defoliation from the Marssonina leaf spot are the principle reasons hybrid poplar trees have not been commercially viable in the Eastern USA versus the Western USA where hybrids are grown for the pulp and paper industry [56]. While these fungal pathogens cause leaf spots and stem cankers, our results also demonstrate that they inhabit soils surrounding the plants and colonize root tissue, although relative abundance is significantly lower (less than $0.1 \%$ ) in these habitats. Fungal pathogens in hybrid trees invade host tissue and may outcompete other fungal species leading to lower diversity in the hybrid fungal microbiome. This pattern is evident in the leaf tissues of the hybrid trees where Marssonina brunnea OTUs have a greater abundance. However, it is noteworthy that Septoria sp. were also present within tissues of both $P$. 


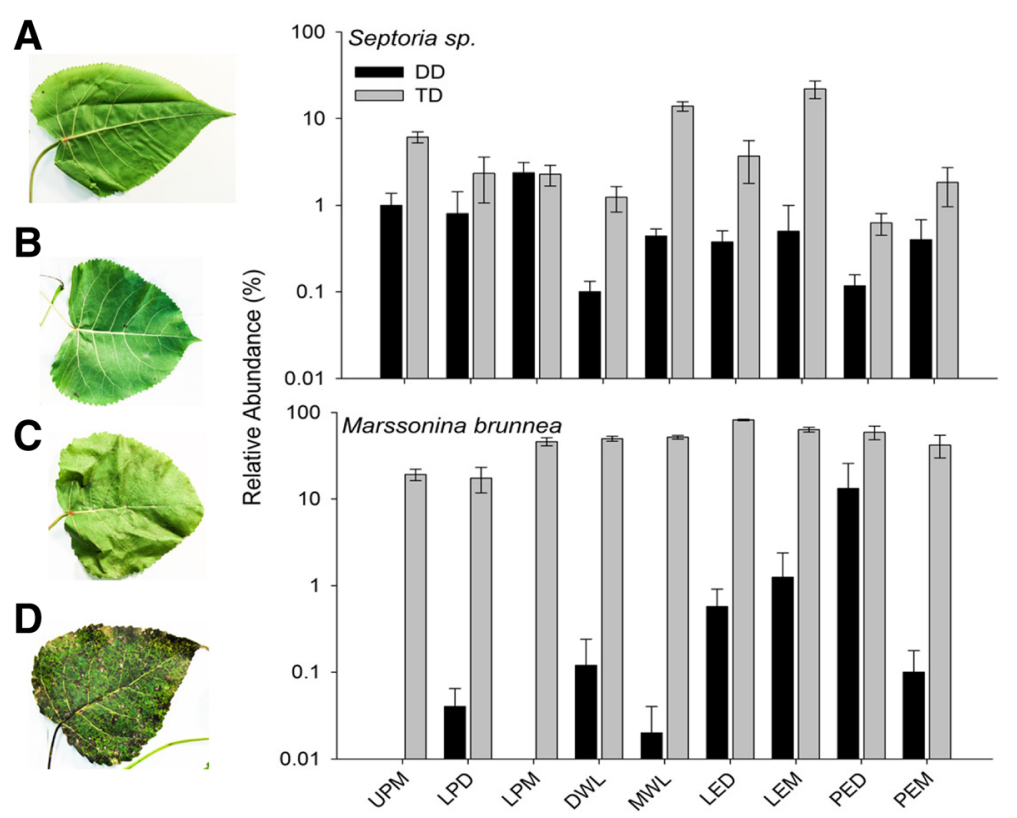

Fig. 5 Log relative abundance of OTUs classified as the Populus leaf pathogens Septoria sp. and Marssonina brunnea across leaf niches within P. deltoides (DD) and $P$. trichocarpa $\times$ deltoides hybrids (TD). Bars represent means \pm SE. Any bars missing indicate that OTU is absent from all samples within that habitat category. Septoria $s p$. and Marssonina brunnea relative abundance differed across habitats and genotypes $(p \leq 0.05)$. Representative of developing vs. mature leaves for Populus deltoides (a vs $\mathbf{b}$ ) and TD hybrids (c vs $\mathbf{d}$ ), respectively. The $X$-axis denotes leaf niche sampled. UPM upper phyllosphere mature, LPD lower phyllosphere developing, LPM lower phyllosphere mature, DWL whole leaf developing phyllosphere, MWL whole leaf mature phyllosphere, LED leaf endosphere developing, LEM leaf endosphere mature, PED petiole endosphere developing, PEM petiole endosphere mature

deltoides and the hybrid trees (Fig. 5) but only manifested disease symptoms in the hybrid. In the hybrid leaf tissues, Septoria OTUs were also at a much lower abundance than Marssonina OTUs (Fig. 2) suggesting that these pathogens are both able to colonize and coexist, but Marssonina may have ecological strategies which allow it to more readily colonize the leaf habitats and proliferate.

\section{Conclusions}

The Populus woody plant system provides a relevant model to examine how microbial communities vary across tissue level niches. Overall, this study demonstrates how niche-based processes, such as environmental filtering or biotic interactions, drive microbiome composition and diversity within tree species. Further, this study indicates the potential importance of microbemicrobe interactions in microbial community composition as indicated by the presence of fungal pathogens which may alter the microorganisms inhabiting the hybrid Populus trees. However, while we suspect that the pathogens are playing a disproportionate role in structuring these communities, future studies will be needed to more carefully address this hypothesis using closely related pathogen-resistant and susceptible Populus genotypes.

\section{Additional files}

Additional file 1: Table S1. Sampling niches across the broad habitats and the three letter unique code for each niche. Table S2. Primer mixtures and PNA PCR blockers used in this study. Sequences in blue represent NextEra annealing sites, black represents the Molecular Identifier Tag including frameshifts, green represents linker adaptors, and red represents PCR primers. Table S3. Two-way ANOVA (habitat $\times$ genotype) $p$ values for Tukey's HSD post hoc pairwise comparisons test in Septoria sp. relative abundance differences across leaf habitats. Models indicate that Septoria $s p$. differed across habitats ( $F$ $=9.34, p \leq 0.01)$ and tree genotypes $(F=56.34, p \leq 0.01)$. Table S4. Two-way ANOVA (habitat $\times$ genotype) $p$ values for Tukey's HSD post hoc pairwise comparisons test in Marssonina brunnea. Relative abundance differences across leaf habitats. Models indicate that Marssonina differed across habitats $(F=6.40, p \leq$ 0.01 ) and tree genotypes ( $F=590.95, p \leq 0.01)$. Table S5. Two-way ANOVA (habitat $\times$ genotype) $p$ values for pairwise comparisons in bacterial diversity across leaf niches. Two-way ANOVA models indicate that bacterial diversity differed within habitats $(F=2.53, p=0.013)$, but not between tree genotypes $(F=$ $0.003, p=0.958$ ). Table S6. Two-way ANOVA (habitat $\times$ genotype) $p$ values for pairwise comparisons in bacterial diversity across stem niches. Two-way ANOVA models indicate that bacterial diversity differed within habitats $(F=2.984, p=$ 0.006), but not between tree genotypes $(F=1.386, p=0.243)$. Table S7. Twoway ANOVA (habitat $\times$ genotype) $p$ values for pairwise comparisons in bacterial diversity across root niches. Two-way ANOVA models indicate that bacterial diversity differed within habitats $(F=11.474, p<0.001)$, but not between tree genotypes ( $F=0.987, p=0.324)$. Table S8. Two-way ANOVA (habitat $\times$ genotype) $p$ values for pairwise comparisons in bacterial diversity across soil niches. Twoway ANOVA models indicate that bacterial diversity differed within habitats ( $F=$ 7.821, $p<0.001)$, but not between tree genotypes $(F=0.297, p=0.589)$. Table S9. Two-way ANOVA (habitat $\times$ genotype) $p$ values for pairwise comparisons in fungal diversity across leaf niches. Two-way ANOVA models indicate that fungal diversity differed within habitats $(F=8.198, p<0.001)$, and between tree genotypes $(F=86.509, p<0.001)$. Table S10. Two-way ANOVA (habitat $\times$ genotype) 
$p$ values for pairwise comparisons in fungal diversity across stem niches. Two-way ANOVA models indicate that fungal diversity differed within habitats $(F=4.568, p<0.001)$, and between tree genotypes $(F=6.127, p=0.015)$. Table S11. Two-way ANOVA (habitat $\times$ genotype) $p$ values for pairwise comparisons in fungal diversity across soil niches. Two-way ANOVA models indicate that fungal diversity differed within habitats $(F=6.026, p=0.002)$, but not between tree genotypes ( $F=0.036, p=0.851$ ). Table S12. Relative abundance of dominant $(\geq 0.1 \%)$ archaeal/bacterial and fungal phyla and class for Proteobacteria across broad habitat categories and genotypes (mean \pm SE). Two-way ANOVA models indicated all bacterial and fungal phyla, except Fusobacteria, differed across habitat $(p \leq 0.01)$ whereas two bacterial phyla differed between genotypes $(p \leq 0.03)$ as denoted by bolded lettering. Letters denote Tukey's HSD significant differences for main effects of habitat and genotype. Figure S1. Sampling schema for 30 plant niches. Each niche was sampled from five replicate Populus deltoides clones and P. trichocarpa $\times$ deltoides hybrid clones, totaling 300 microbiome samples. Figure S2. Performance of plant nuclear 5.8S rRNA gene targeted peptide nucleic acid (PNA) blocker in select fungal ITS2 amplicon libraries. We used two different tissue types including fine root endosphere (SFR), developing leaf endosphere (LED), as well as rhizosphere soils. These are tested on samples originating from Populus deltoides (DD1) and a P. trichocarpa $\times$ deltoides hybrid (TD1). Samples with PNA blockers added are indicated by _PNA at the end of name. Figure S3. Rarefaction curves for bacteria across broad habitat classifications (leaves—red, stems—green, roots—-blue, soil—orange) at 1000 sequences per sample depth. Figure S4. Rarefaction curves for fungi across broad habitat classifications (leaves-red, stems - green, rootsblue, soil—orange) at 2000 sequences per sample depth. (DOCX $3250 \mathrm{~kb}$ )

\section{Acknowledgements}

The authors would like to thank Dale Pelletier, Jessica Velez, Sara Jawdy, Lee Gunter, Kenneth Lowe, Tatiana Karpinets, and Renee Johansen for their assistance with the field work, as well as Timothy Rials, The University of Tennessee Institute of Agriculture, and ArborGen Corporation for providing the site access and allowing us to harvest the trees from their field trial.

\section{Funding}

This research was sponsored by the Genomic Science Program, U.S. Department of Energy, Office of Science, Biological and Environmental Research, as part of the Plant Microbe Interfaces Scientific Focus Area at ORNL (http://pmi.ornl.gov). Oak Ridge National Laboratory is managed by UT-Battelle, LLC, for the U.S. Department of Energy under contract DEAC05-000R22725.

\section{Availability of data and materials}

The sequence datasets generated during the current study are available at NCBI Sequence Read Archive: 16S-BioProject ID: PRJNA385484 and ITS2BioProject ID: PRJNA384978.

\section{Authors' contributions}

CS designed the study. ZY, RV, and CS collected samples. MAC, AV, MC, and $Z Y$ prepared the samples for amplicon sequencing. MAC and AV performed the bioinformatics and statistical analyses. MAC, AV, and CS contributed to statistical interpretation of results. MAC, AV, ZY, GT, RV, and CS wrote the manuscript. All authors read and approved the final manuscript.

\section{Ethics approval and consent to participate}

Not applicable

\section{Consent for publication}

Not applicable

\section{Competing interests}

The authors declare that they have no competing interests.

\section{Publisher's Note}

Springer Nature remains neutral with regard to jurisdictional claims in published maps and institutional affiliations.

\section{Author details}

'Biosciences Division, Oak Ridge National Laboratory, 1 Bethel Valley Rd, Oak Ridge, TN 37831, USA. ${ }^{2}$ Biology Department, Duke University, 130 Science Drive, Durham, NC 27708, USA. ${ }^{3}$ Microbiology Department, University of
Tennessee, M409 Walters Life Sciences, Knoxville, TN 37996, USA. ${ }^{4}$ Present address: Department of Biochemistry \& Molecular Biology, Brody School of Medicine, East Carolina Diabetes \& Obesity Institute, East Carolina University, Greenville, NC, USA.

Received: 28 July 2017 Accepted: 23 January 2018

Published online: 12 February 2018

\section{References}

1. Pii Y, Mimmo T, Tomasi N, Terzano R, Cesco S, Crecchio C. Microbial interactions in the rhizosphere: beneficial influences of plant growthpromoting rhizobacteria on nutrient acquisition process. A review. Biol Fertil Soils. 2015;51:403-15.

2. de Zelicourt A, Al-Yousif M, Hirt H. Rhizosphere microbes as essential partners for plant stress tolerance. Mol Plant. 2013;6:242-5.

3. Berendsen RL, Pieterse CMJ, Bakker PAHM. The rhizosphere microbiome and plant health. Trends Plant Sci. 2012;17:478-86.

4. Pineda A, Soler R, Pozo MJ, Rasmann S, Turlings TCJ. Editorial: abovebelowground interactions involving plants, microbes and insects. Front Plant Sci. 2015:6:318.

5. Hacquard S, Schadt CW. Towards a holistic understanding of the beneficial interactions across the Populus microbiome. New Phytol. 2015;205:1424-30

6. Vandenkoornhuyse P, Quaiser A, Duhamel M, Le Van A, Dufresne A. The importance of the microbiome of the plant holobiont. New Phytol. 2015; 206:1196-206

7. Pinto C, Pinho D, Sousa S, Pinheiro M, Egas C, Gomes AC. Unravelling the diversity of grapevine microbiome. PLoS One. 2014;9:e85622

8. Ottesen AR, Pena AG, White JR, Pettengill JB, Li C, Allard S, Rideout S, Allard M, Hill T, Evans P, et al. Baseline survey of the anatomical microbial ecology of an important food plant: Solanum lycopersicum (tomato). BMC Microbiol. 2013;13:114

9. Beckers B, Op De Beeck M, Weyens N, Boerjan W, Vangronsveld J. Structural variability and niche differentiation in the rhizosphere and endosphere bacterial microbiome of field-grown poplar trees. Microbiome. 2017;5:25

10. Coleman-Derr D, Desgarennes D, Fonseca-Garcia C, Gross S, Clingenpeel S, Woyke T, North G, Visel A, Partida-Martinez LP, Tringe SG. Plant compartment and biogeography affect microbiome composition in cultivated and native Agave species. New Phytol. 2016;209:798-811.

11. de Souza RSC, Okura VK, JSL A, Jorrin B, Lozano N, da Silva MJ, GonzalezGuerrero M, de Araujo LM, Verza NC, Bagheri HC, et al. Unlocking the bacterial and fungal communities assemblages of sugarcane microbiome. Sci Rep. 2016;6:28774.

12. Leff JW, Del Tredici P, Friedman WE, Fierer N. Spatial structuring of bacterial communities within individual Ginkgo biloba trees. Environ Microbiol. 2015; 17:2352-61.

13. Zarraonaindia I, Owens SM, Weisenhorn P, West K, Hampton-Marcell J, Lax S, Bokulich NA, Mills DA, Martin G, Taghavi S, et al. The soil microbiome influences grapevine-associated microbiota. MBio. 2015;6:e02527-14.

14. Tuskan GA, DiFazio S, Jansson S, Bohlmann J, Grigoriev I, Hellsten U, Putnam N, Ralph S, Rombauts S, Salamov A, et al. The genome of black cottonwood, Populus trichocarpa (Torr. \& Gray). Science. 2006;313:1596-604.

15. Tuskan GA, DiFazio SP, Teichmann T. Poplar genomics is getting popular: the impact of the poplar genome project on tree research. Plant Biol. 2004;6:2-4.

16. Dinus RJ, Payne P, Sewell NM, Chiang VL, Tuskan GA. Genetic modification of short rotation popular wood: properties for ethanol fuel and fiber productions. Crit Rev Plant Sci. 2001:20:51-69.

17. Tuskan GA. Short-rotation woody crop supply systems in the United States: what do we know and what do we need to know? Biomass Bioenergy. 1998;14:307-15

18. Sannigrahi P, Ragauskas AJ, Tuskan GA. Poplar as a feedstock for biofuels: a review of compositional characteristics. Biofuels Bioprod Biorefin. 2010;4 209-26.

19. Ragauskas AJ, Beckham GT, Biddy MJ, Chandra R, Chen F, Davis MF, Davison $\mathrm{BH}$, Dixon RA, Gilna $\mathrm{P}$, Keller M, et al. Lignin valorization: improving lignin processing in the biorefinery. Science. 2014;344:1246843.

20. Rubin EM. Genomics of cellulosic biofuels. Nature. 2008;454:841-5.

21. Gottel NR, Castro HF, Kerley M, Yang ZM, Pelletier DA, Podar M, Karpinets T, Uberbacher E, Tuskan GA, Vilgalys R, et al. Distinct microbial communities within the endosphere and rhizosphere of Populus deltoides roots across contrasting soil types. Appl Environ Microbiol. 2011;77:5934-44. 
22. Shakya M, Gottel N, Castro H, Yang ZMK, Gunter L, Labbe J, Muchero W, Bonito $\mathrm{G}$, Vilgalys $\mathrm{R}$, Tuskan $\mathrm{G}$, et al. A multifactor analysis of fungal and bacterial community structure in the root microbiome of mature Populus deltoides trees. PLoS One. 2013;8:e76382.

23. Bonito G, Reynolds H, Robeson MS, Nelson J, Hodkinson BP, Tuskan G, Schadt CW, Vilgalys R. Plant host and soil origin influence fungal and bacterial assemblages in the roots of woody plants. Mol Ecol. 2014;23:3356-70.

24. Taghavi S, Garafola C, Monchy S, Newman L, Hoffman A, Weyens N, Barac T, Vangronsveld J, van der Lelie D. Genome survey and characterization of Endophytic bacteria exhibiting a beneficial effect on growth and development of poplar trees. Appl Environ Microbiol. 2009;75:748-57.

25. Henning JA, Weston DJ, Pelletier DA, Timm CM, Jawdy SS, Classen AT. Root bacterial endophytes alter plant phenotype, but not physiology. PeerJ. 2016;4: e2606

26. Timm CM, Pelletier DA, Jawdy SS, Gunter LE, Henning JA, Engle N, Aufrecht J, Gee E, Nookaew I, Yang ZM, et al. Two poplar-associated bacterial isolates induce additive favorable responses in a constructed plant-microbiome system. Front Plant Sci. 2016;7:497.

27. Newcombe G, Ostry N. Recessive resistance to Septoria stem canker of hybrid poplar. Phytopathology. 2001;91:1081-4.

28. Busby PE, Newcombe G, Dirzo R, Whitham TG. Genetic basis of pathogen community structure for foundation tree species in a common garden and in the wild. J Ecol. 2013;101:867-77.

29. Busby PE, Peay KG, Newcombe G. Common foliar fungi of Populus trichocarpa modify Melampsora rust disease severity. New Phytol. 2016;209: 1681-92.

30. Badri DV, Vivanco JM. Regulation and function of root exudates. Plant Cell Environ. 2009:32:666-81.

31. Richter-Heitmann T, Eickhorst T, Knauth S, Friedrich MW, Schmidt H. Evaluation of strategies to separate root-associated microbial communities: a crucial choice in Rhizobiome research. Front Microbiol. 2016;7:773

32. Lundberg DS, Yourstone S, Mieczkowski P, Jones CD, Dangl JL. Practical innovations for high-throughput amplicon sequencing. Nat Methods. 2013; 10:999-1002.

33. Caporaso JG, Kuczynski J, Stombaugh J, Bittinger K, Bushman FD, Costello EK, Fierer N, Pena AG, Goodrich JK, Gordon Jl, et al. QIIME allows analysis of high-throughput community sequencing data. Nat Methods. 2010;7:335-6.

34. Martin M. Cutadapt removes adapter sequences from high-throughput sequencing reads. EMBnet J. 2011;17:10

35. Edgar RC. Search and clustering orders of magnitude faster than BLAST. Bioinformatics. 2010;26:2460-1.

36. Abarenkov $\mathrm{K}$, Nilsson $\mathrm{RH}$, Larsson $\mathrm{KH}$, Alexander IJ, Eberhardt U, Erland S, Hoiland K, Kjoller R, Larsson E, Pennanen T, et al. The UNITE database for molecular identification of fungi - recent updates and future perspectives. New Phytol. 2010;186:281-5.

37. Anderson MJ. A new method for non-parametric multivariate analysis of variance. Aus Ecol. 2001;26:32-46.

38. Herve M. Testing and plotting procedures for biostatistics. In: Package 'RVAideMemoire'; 2018.

39. De Caceres M, Legendre $P$. Associations between species and groups of sites: indices and statistical inference. Ecology. 2009;90:3566-74.

40. Nguyen NH, Song ZW, Bates ST, Branco S, Tedersoo L, Menke J, Schilling JS, Kennedy PG. FUNGuild: an open annotation tool for parsing fungal community datasets by ecological guild. Fungal Ecol. 2016;20:241-8.

41. Edwards J, Johnson C, Santos-Medellin C, Lurie E, Podishetty NK, Bhatnagar S, Eisen JA, Sundaresan V. Structure, variation, and assembly of the rootassociated microbiomes of rice. Proc Natl Acad Sci U S A. 2015:112:E911-20.

42. Emerson BC, Gillespie RG. Phylogenetic analysis of community assembly and structure over space and time. Trends Ecol Evol. 2008:23:619-30.

43. Zamioudis C, Pieterse CMJ. Modulation of host immunity by beneficial microbes. Mol Plant-Microbe Interact. 2012;25:139-50.

44. Whipps JM, Hand P, Pink D, Bending GD. Phyllosphere microbiology with special reference to diversity and plant genotype. J Appl Microbiol. 2008; 105:1744-55.

45. Peay KG, Kennedy PG, Talbot JM. Dimensions of biodiversity in the Earth mycobiome. Nat Rev Microbiol. 2016;14:434-47.

46. Baum C, Makeschin F. Effects of nitrogen and phosphorus fertilization on mycorrhizal formation of two poplar clones (Populus trichocarpa and Ptremula x tremuloides). J Plant Nutr Soil Sci. 2000;163:491-7.
47. Mendes R, Garbeva P, Raaijmakers JM. The rhizosphere microbiome: significance of plant beneficial, plant pathogenic, and human pathogenic microorganisms. FEMS Microbiol Rev. 2013;37:634-63.

48. Wu HS, Liu DY, Ling N, Bao W, Ying RR, Ou YH, Huo ZH, Li YF, Shen QR. Effects of vanillic acid on the growth and development of Fusarium oxysporum f. sp niveum. Allelopath J. 2008:22:111-21.

49. Knoth JL, Kim SH, Ettl GJ, Doty SL. Biological nitrogen fixation and biomass accumulation within poplar clones as a result of inoculations with diazotrophic endophyte consortia. New Phytol. 2014;201:599-609.

50. Schink B, Ward JC, Zeikus JG. Microbiology of wetwood-role of anaerobic bacterial-populations in living trees. J Gen Microbiol. 1981;123:313-22.

51. Zeikus JG, Ward JC. Methane formation in living trees-microbial origin. Science. 1974;184:1181-3.

52. Doty SL, Sher AW, Fleck ND, Khorasani M, Bumgarner RE, Khan Z, Ko AWK, Kim SH, DeLuca TH. Variable nitrogen fixation in wild populus. PLoS One. 2016;11:e0155979

53. Telewski FW, Aloni R, Sauter JJ. Physiology of secondary tissues of Populus. In: Biology of Populus and its implications for management and conservation. Ottawa: NRC Research Press; 1996. p. 301-29.

54. Groover AT, Nieminen K, Helariutta Y, Mansfield SD. Wood formation in Populus. In: Genetics and genomics of Populus. New York: Springer; 2010. p. 201-24.

55. Zhu S, Cao YZ, Jiang C, Tan BY, Wang Z, Feng SS, Zhang L, Su XH, Brejova B, Vinar $T$, et al. Sequencing the genome of Marssonina brunnea reveals fungus-poplar co-evolution. BMC Genomics. 2012;13:382

56. Ostry ME. Biology of Septoria Musiva and Marssonina-Brunnea in hybrid Populus plantations and control of Septoria canker in nurseries. Eur J For Pathol. 1987;17:158-65.

\section{Submit your next manuscript to BioMed Central and we will help you at every step:}

- We accept pre-submission inquiries

- Our selector tool helps you to find the most relevant journal

- We provide round the clock customer support

- Convenient online submission

- Thorough peer review

- Inclusion in PubMed and all major indexing services

- Maximum visibility for your research

Submit your manuscript at www.biomedcentral.com/submit 